\title{
Skin Development in $H$. huso Larvae
}

\author{
H. Fazel Shooraki ${ }^{1} \quad$ Z. Saadatfar ${ }^{1} \quad$ D. Shahsavani ${ }^{2}$ \\ ${ }^{1}$ Department of Anatomical Science, School of Veterinary Medicine, \\ Ferdowsi University of Mashhad, Khorasan Razavi, Mashhad, Iran \\ 2 Department of Food Hygiene and Aquaculture, School of Veterinary \\ Medicine, Ferdowsi University of Mashhad, Khorasan Razavi, \\ Mashhad, Iran
}

\author{
Address for correspondence Z. Saadatfar, Department of Anatomical \\ Science, School of Veterinary Medicine, Ferdowsi University of \\ Mashhad, Khorasan Razavi, Mashhad, Iran \\ (e-mail: saadatfar@ferdowsi.um.ac.ir).
}

J Morphol Sci 2018;35:37-43.

\begin{abstract}
Keywords

- huso huso

- skin development

- histolog

Introduction Fish skin is important for life and protection mechanisms. Sturgeon skin also has an economical potential for its leather.

Materials and Methods This article is a light microscopy study for knowledge the development of epidermis and dermis in one species of sturgeon (Huso. huso). The fishes from different days of week- 1 to week- 6 were caught from Shahid Marjani propagation center and were processed.

Results From 1(dph) the epidermis as two layers and dermis as a very thin collagen layer had formed. Sensory buds in epidermis and chromatophore cells in dermis of head and also arranged the dermal endothelial cells were features of 3 (dph). At 10 (dph) there was an increase in epidermal cell line, existence the circular cells as club cells in epidermis and increase in dermal thickness observed. From the character of 20 (dph) was organized epidermis to three layers and collagen fibrils as parallel to body. From 2540 (dph) an increase in cell lines of epidermis up to 10 rows in some areas was observed. Conclusion The most important changes were the events occurred in dermis. The self-organized collagen fibrils to several lamellae, invading the fibroblasts to derm and forms of stratum campactum and stratum spongiosum.
\end{abstract}

\section{Introduction}

Skin is a complex tissue and the first extensive interface between the animal and its external environment. In fishes, skin has a major role from the view of adaptation to the environment. In addition to physical protection, it helps to maintain the osmotic balance, accommodates hydrodynamics, and has sensory receptors and can takes part in respiration by the exchange of oxygen and carbon dioxide through the numerous blood vessels near the skin surface. Because it aids to skeletal support, in swimming mechanics has basic role and muscle force transmit down the body through the skin. ${ }^{1}$ It differs from the skin of other vertebrates for the living surface cells which are in direct contact with the aqueous environment and presence a mucous layer instead of keratin. ${ }^{2}$ The mucus coat maintains the water balance, and enzymes and antibodies which protects fish from infectious of bacteria. In several species, the skin also protect through control of coloration by expansion and contraction of the chromatophores.

The structure of fish skin has interested researchers for a long time. It is composed of three compartments: epidermis, dermis and hypodermis. Fish epidermis can be subdivided into surface, intermediate and basal layers. In contrast to terrestrial vertebrates which epidermis is covered by a layer of dead and keratinized cells, in fish it comprises from living cells exception specified sites that are subjected to abrasion such as lips and pads and the epidermal surface of some species capable of emerging from the water. ${ }^{3}$ The surface epidermal cells are as a single cell layer through its microfilament can protects the animal against different shocks. It is not renewed periodically, but when dead it can replace. received

February 13, 2017

accepted

February 14, 2018
DOI https://doi.org/

10.1055/s-0038-1660491. ISSN 2177-0298.
Copyright $\odot 2018$ by Thieme Revinter

Publicações Ltda, Rio de Janeiro, Brazil
License terms

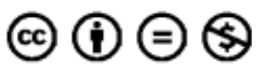


The intermediate layer is composed of various types of cells, the unicellular glands such as mucous goblet cells and club cells that produce alarm substances, epidermal ionocytes in some species are ion transporters and maintain the homeostasis of body fluids, sensory buds and the most dominant undifferentiated cells that when necessary can divide rapidly and serve as a reservoir for dead cells. The basal layer cells are as a single cell layer which keeps the epidermis to the basement membrane by means of hemidesmosomes. However other functions such as production of the early collagen stroma, interaction with the underlying mesenchymal cells for development of the dermal skeleton also imputation to basal layer in developmental stages. Variation in cell composition and in thickness of epidermis that usually concern to intermediate layer is related to the ecological adaptations of the species. ${ }^{2,3}$

The dermis divided into superficial region (stratum laxum) and the deep region (stratum compactum). Stratum laxum is composed of a loose connective tissue and the stratum compactum is a dense collagen plywood-like tissue with fibrocytes that in some places the vertical bundles of collagen fibers from this penetrated between muscles. So collagen organization is to strengthen the skin against tensile forces. The lamellar form of stratum compactum can causes the transparency of tissue. ${ }^{4}$ Under the collagenous fibers, the chromatophores are located and therefore the transparency can be important for the function of these cells. The thick dermis of naked fishes is interest to the leather industry.

The hypoderm separates the derm from the muscle fibers and is composed of a space containing of loose connective tissue and chromatophores, the fibrocyte like cells bordered the hypoderm on both sides and named dermal endothelium. $^{5}$

The sturgeon, Huso huso is one of the most valuable species of Acipenseridea that widely distributed in the southern basin of the Caspian Sea and as other sturgeon, this species also has diminished and is in danger of extinction. ${ }^{6}$ This species is used for commercial food products such as caviar and smoked sturgeon meat. Sturgeon skin has special morphological, histological and physiological characteristics such as a beautiful appearance and a well balanced thickness and flexibility, makes it suitable for production of high quality leather and related products as clothing, shoes and handbags. ${ }^{7,8}$ Sturgeon production is considered as a business with great economic potential. This production can often accompany by the risk of infection and knowledge about skin development as a protective barrier against aquatic environment, can reduce the risk of diseases in aquaculture. The present study will help to understand the process of skin development and also to diagnose and treat fish skin diseases.

\section{Materials and Methods}

Five Huso huso larvae from each of 1 (dph), 3 (dph), 7 (dph), 10 (dph), 15 (dph), 20 (dph), 25 (dph), 30 (dph) and 40 (dph) were obtained from Shahid Marjani propagation center in Gorgan. The larvae were kept in fiberglass tanks to 21 (dph) and then, they were transfered to pond until the age of 45 days. The speciemens were fixed in $10 \%$ neutral buffered formaldehyde and transferred to laboratory, dehydrated in graded ethanol, cleared in xylene and embedded in paraffin, cut into $6 \mu \mathrm{m}$ thick sections. Then mounted on glass slides and stained with Haematoxylin-eosin (H\&E) for general studies, Masson's Trichrome (M.T) for collagen, PAS and Alcian blue $(A B)$ for mucous substances. Then they were studied using light microscopy.

\section{Results}

In the first day after hatching (1dph), the epidermis of Huso huso consisted of two cell layers, the surface layer and the basal layer. They were cuboidal and columnar cells with not reaction to $P A S$ and $A B$, although a mucous layer was observed on the surface of epithelium. There was a very thin collagenous layer observed by M.T staining, but the main tissue constitute the dermis was mesenchyme (-Figs. 1 and 2). It must be noticed that from the first day, the thickness of epiderm varied depending on the body region.

At 3 (dph), the skin had no change compared with $1 \mathrm{dph}$ (-Fig. 3). At (7dph), in some parts of head a third to fourth row was formed and the epidermis had thickened. Sensory buds began to form on the epidermis of the head. An obvious collagen layer named as primary dermal stroma with a few chromatophore was observed and in some regions, it was lined by squamous cells, called dermal endothelial cells (-Figs. 4 and 5).

At 10 (dph) and 15 (dph) the epidermis composed of 2-4 row of epithelial cells with large circular or elongated cells and few reaction to PAS and $A B$ staining. At $15 \mathrm{dph}$ an increase in large and light circular or elongated cells that some of them had positive reaction to PAS and AB staninig. The sensory buds were obvious and formed only on the head epidermis. The primary dermal stroma was thickened and it was shown chromatophores at the deep of derm. The skin was separated from the muscle fibers by a distance and the deep and surface of the primary stroma was lined by dermal endothelial cells (-Figs. 6-9).

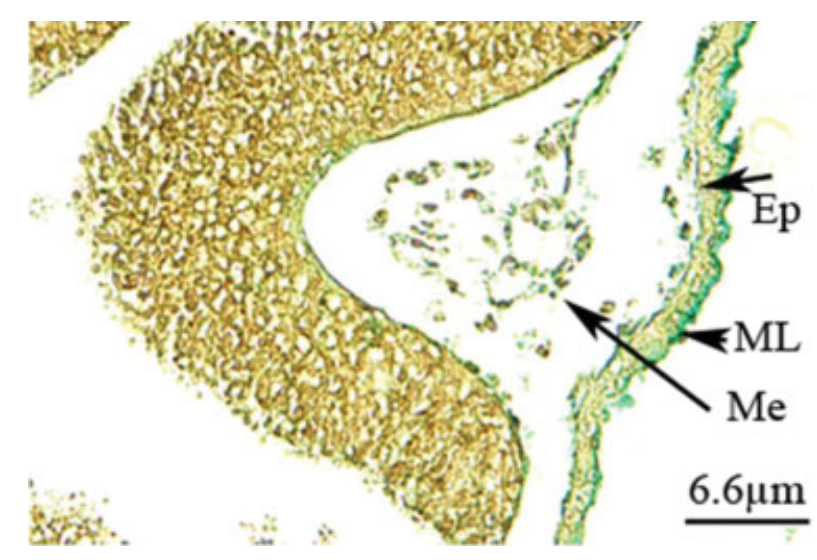

Fig. 1 Histological section of the head skin in 1 day old larvae (AB). Abbreviations: ML, mucous layer; Ep, epiderm; Me, mesenchym; bar $=6.6 \mu \mathrm{m}$. 


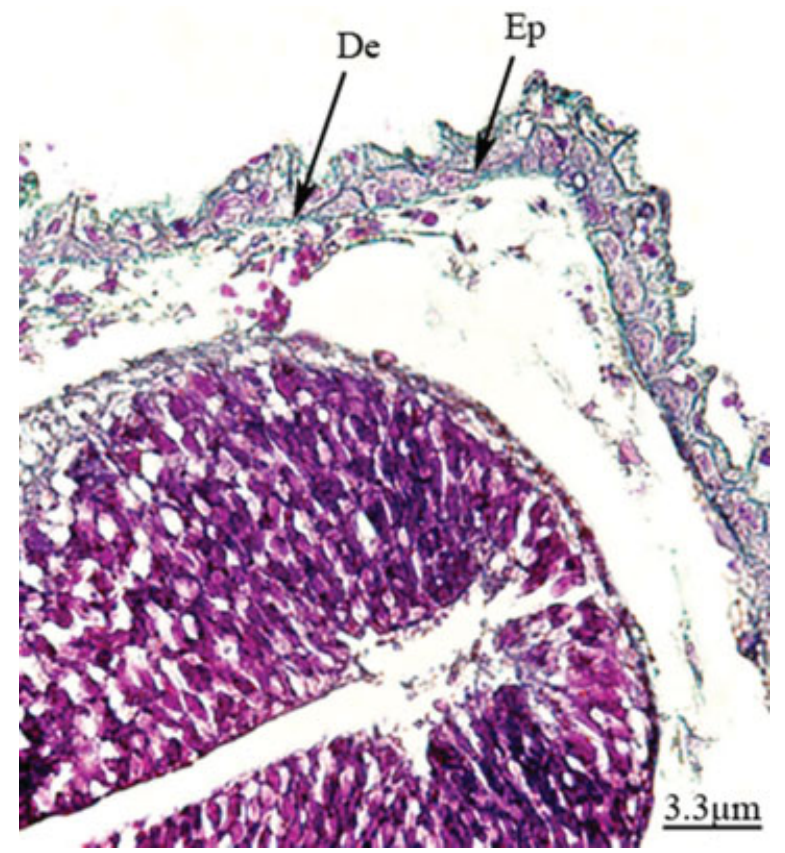

Fig. 2 Histological section of the head skin in 1 day larvae (M.T). Abbreviations: Ep epiderm; De, derm; bar $=3.3 \mu \mathrm{m}$.

At (20 dph), there were remarkable changes in the feature and organization of skin. The epidermis was composed of three cell layer. The superficial squamous to cuboidal cell layer, intermediate flat and large circular to elongated cell layer and the basal cuboidal cell layer. The collagen fibers of derm had changed their orientation from an irregularly to

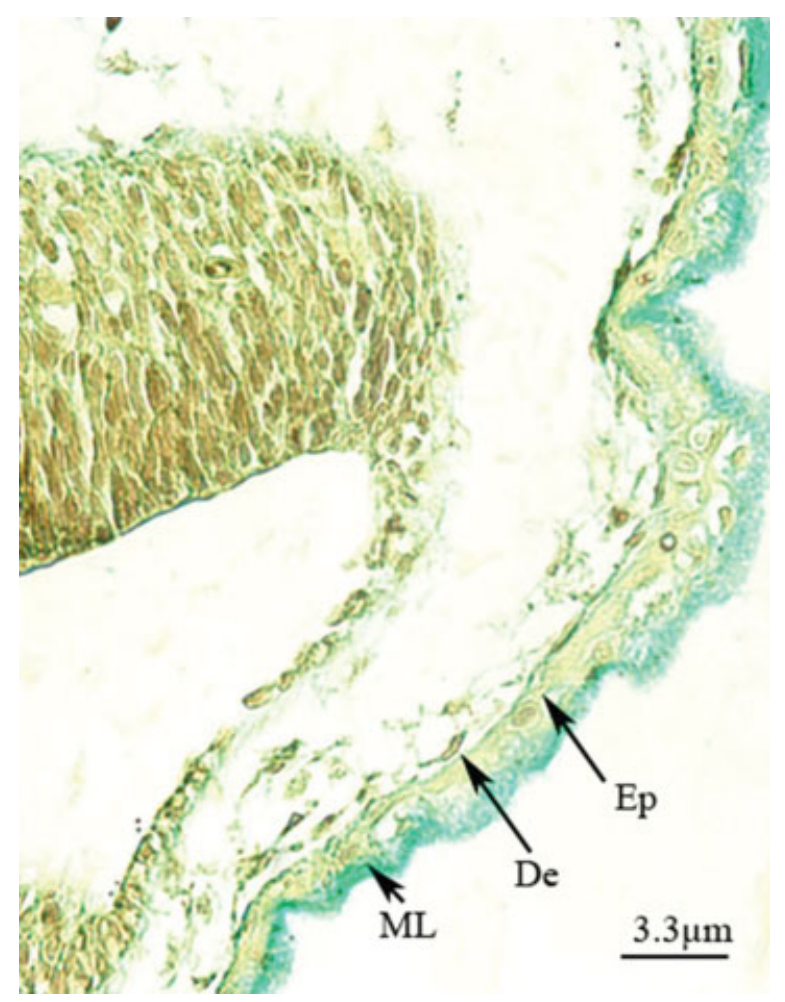

Fig. 3 Histological section of the head skin in 3 day larvae (AB). Abbreviations: Ep, epiderm; De, derm; ML, mucous layer; bar $=3.3 \mu \mathrm{m}$.

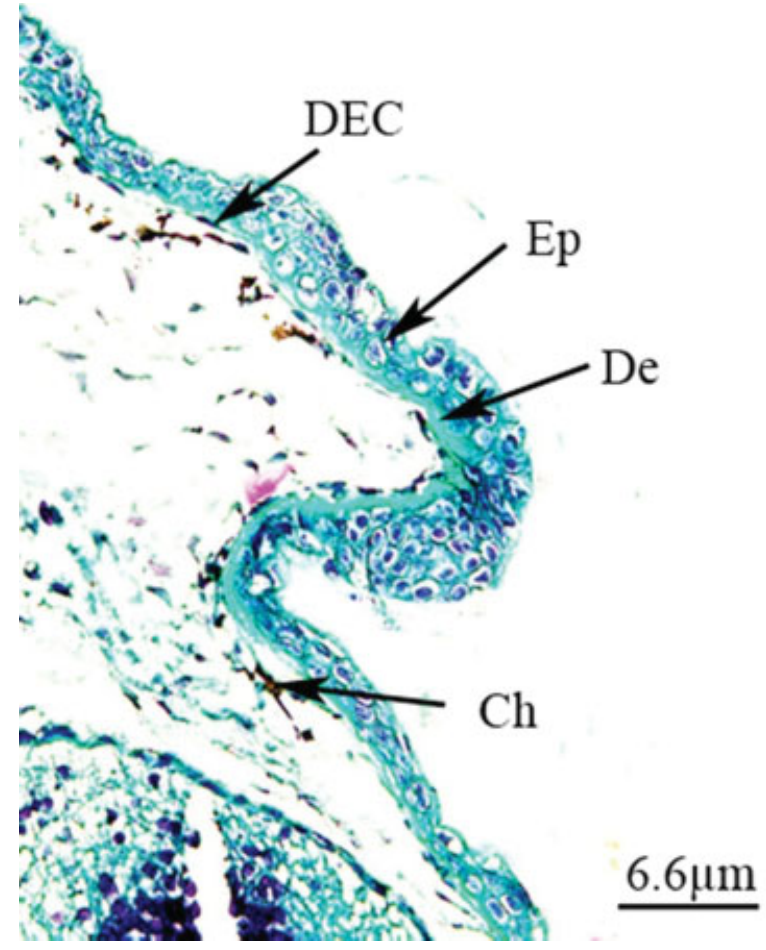

Fig. 4 Histological section of the head skin in 7 day larvae (M.T). Abbreviations: Ep, epiderm; De, derm; DEC, dermal endothelial cells; Ch, chromatophore; bar $=6.6 \mu \mathrm{m}$.

parallel fibrils covered by endothelial cells. Adjacent dermal endothelial, the deep surface of the dermis was lined by chromatophores. In some areas that muscle fibers had been formed, the dermal stroma penetrated by vertical bundles of collagen fibers into muscles. These bundles were also lined by dermal endothelial cells (- Fig. 10).

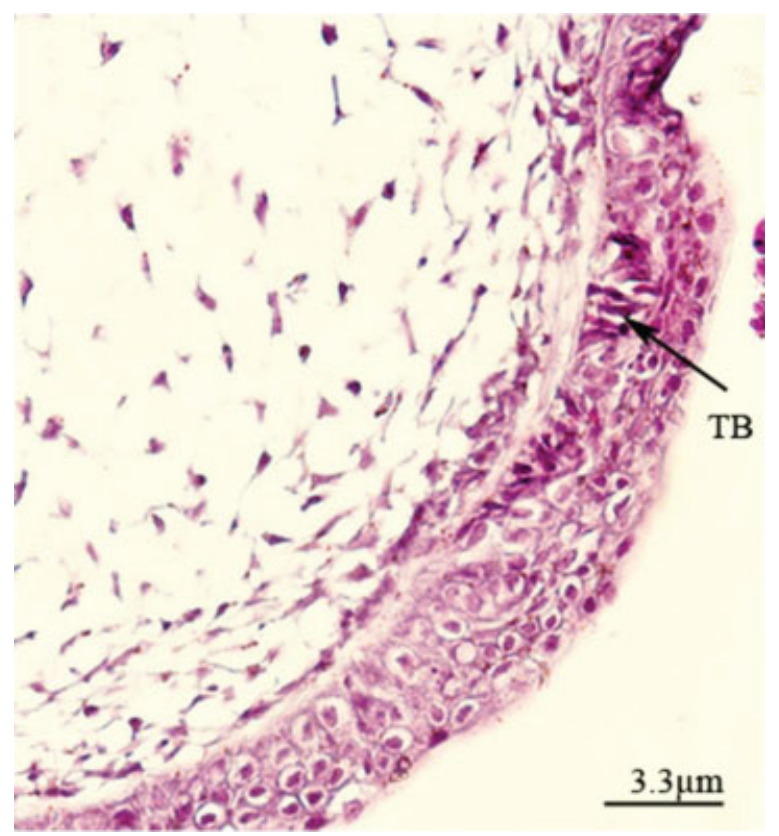

Fig. 5 Histological section of the head skin in 7 day larvae (H\&E). Abbreviations: TB, taste bud; bar $=3.3 \mu \mathrm{m}$. 


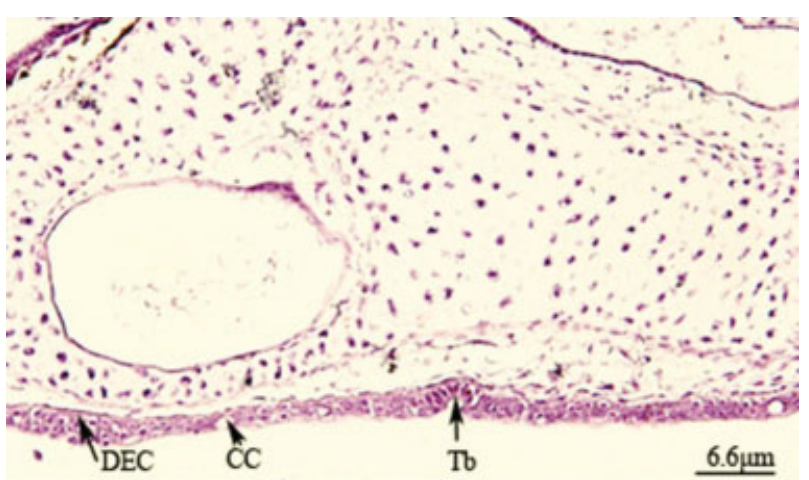

Fig. 6 Histological section of the head skin in 10 day larvae (H\&E). Abbreviations: Tb, taste bud; DEC, dermal endothelial cells; CC, circular cell; bar $=6.6 \mu \mathrm{m}$.

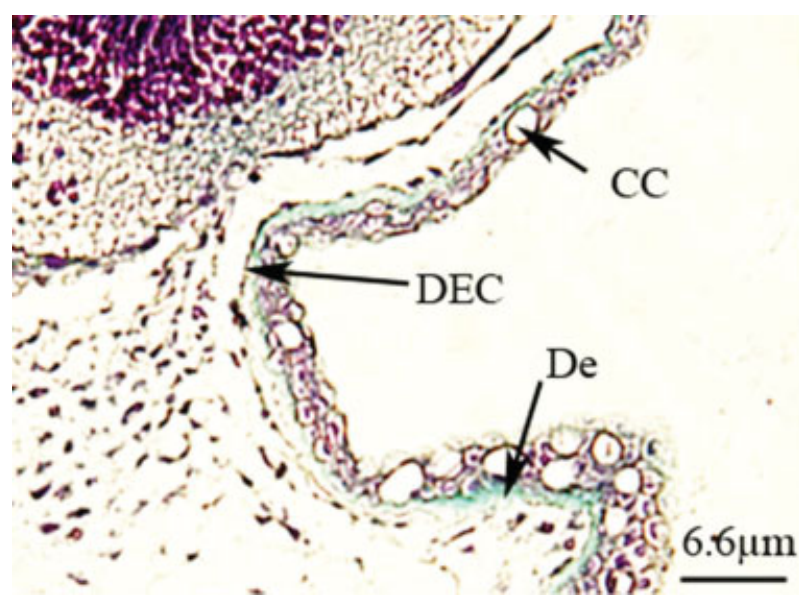

Fig. 7 Histological section of the head skin in 10 day larvae (M.T). Abbreviations: De, derm; DEC, dermal endothelial cells; CC, circular cell; bar $=6.6 \mu \mathrm{m}$.

At 25-40 (dph), remarkable changes in skin thickness was observed. The epidermis of certain regions of the head were thickest, composed up to 10 row and in different parts of trunk it was up to 4 row that as in previous stage they were

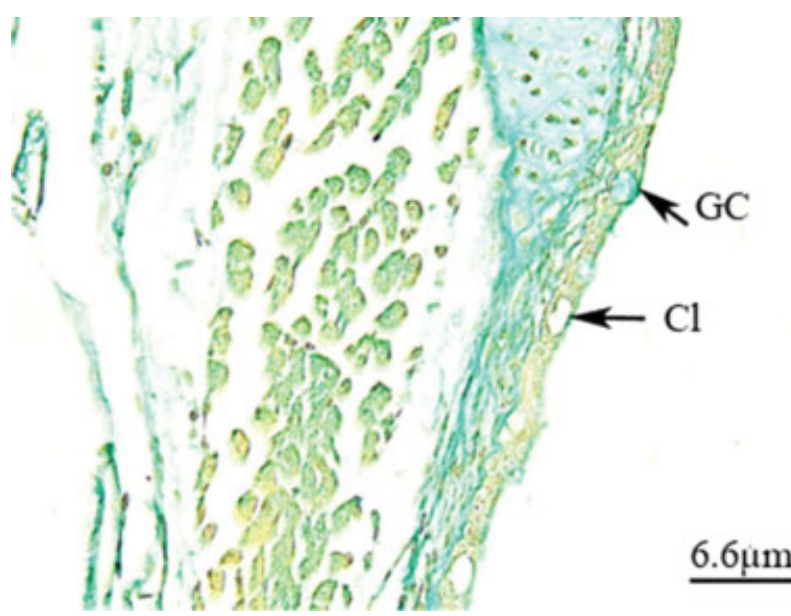

Fig. 8 Histological section of the trunk skin in 15 day larvae (AB). Abbreviations: $\mathrm{Cl}$, club cell; GC, goblet cell; bar $=6.6 \mu \mathrm{m}$.

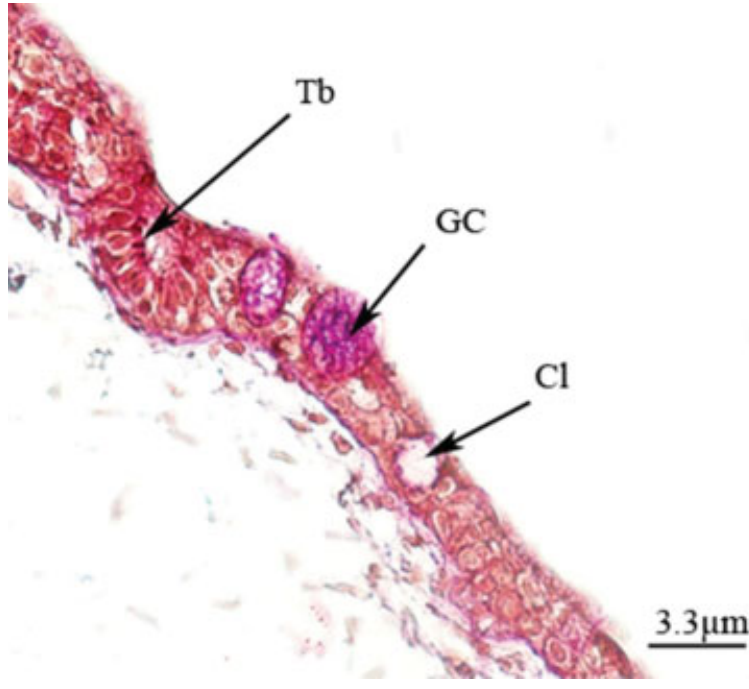

Fig. 9 Histological section of the head skin in 15 day larvae (PAS). Abbreviations: $\mathrm{Cl}$, club cell; GC, goblet cell; Tb, taste bud; bar $=3.3 \mu \mathrm{m}$.

organized in three layers. The superficial cells were squamous to cuboidal, located on the surface of the epithelium and its outer surface seemed to have microridge. The epithelium of intermediate layer composed from two morphologically distinct cell types, the flat cells with condensed chromatin spread throughout the epithelium and the large elongated or circular cells were arranged in two rows in some areas with thick epidermis. This was a common feature for club cells, ionocytes and mucous cells, by light microscopy they were easily identified with their reaction to PAS and $A B$ staining. Mucous cells were characterized by their containing filled with PAS positive secretion, distributed in the middle and superficial layers and open onto the surface, the ionocyes also have free surface and no reaction to PAS but most club cells were covered by the superficial layer. The sensory buds in Huso huso were observed in the head, lip, bronchial and fascial skin as fusiform pale staining structures containing tall columnar cells with oval nuclei. The basal part of the

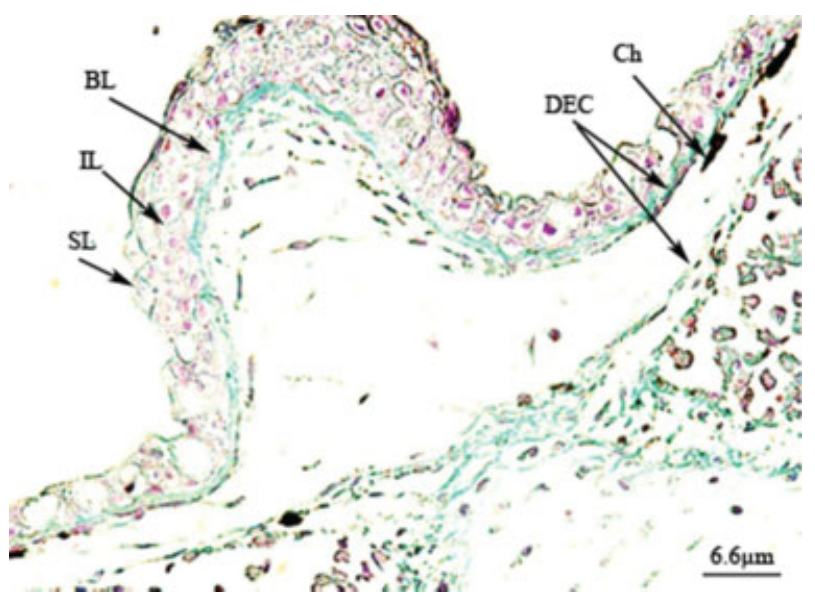

Fig. 10 Histological section of the trunk skin in 20 day larvae (M.T). Abbreviations: SL, Superficial layer; IL, intermediate layer; BL, basal layer; DEC, dermal endothelial cells; Ch, chromatophore. Bar $=6.6 \mu \mathrm{m}$. 


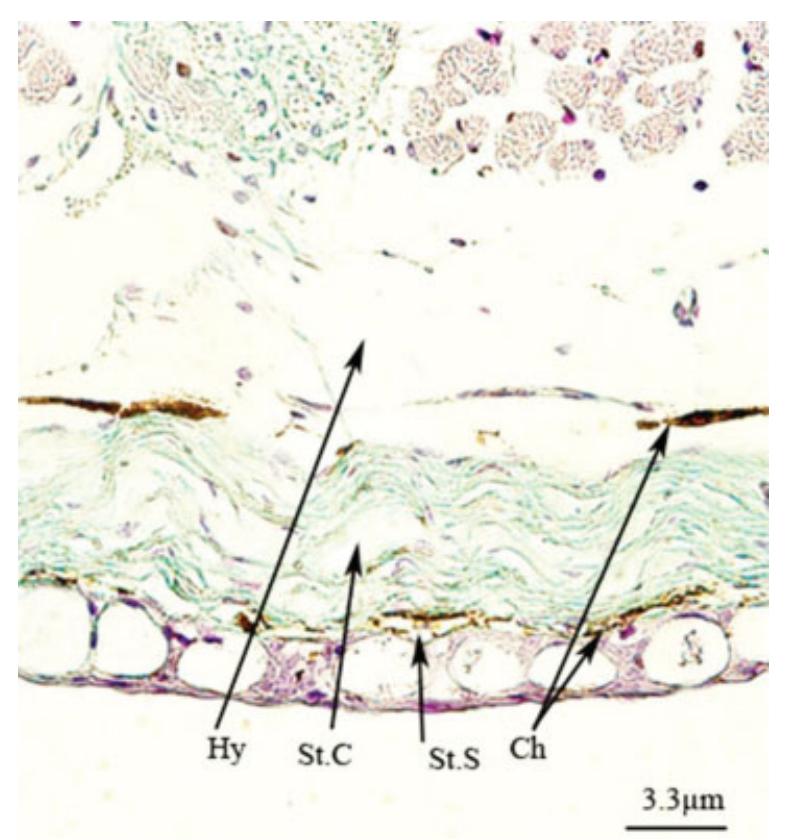

Fig. 11 Histological section of the trunk skin in 40 day larvae (M.T). Abbreviations: Ch, chromatophore; St.S, stratum spongiosum; St.C, stratum compactum; Hy, hypodermis; bar $=3.3 \mu \mathrm{m}$.

epidermis was a single cell layer of cuboidal cells. From 25 (dph) Most changes were obvious at derm of trunk. The collagen fibers were organized to layers called lamellae, so at 40 (dph) in certain areas of trunk the lamellae had increased to 10-12 layers. Other feature of derm from 25 (dph) was the change from a cellular to cellular dermis and primary derm changed into a secondary derm called stratum campactum. From 40 (dph) up of derm in trunk regional so showed a thin cellular layer with a few pigment cells considered as stratum spongiosum. It must be mentioned, at the deep surface of stratum compactum also pigment cells were visible and this region considered as hypodermis (-Fig. 11). This layer was situated between stratum compactum and muscle. It shows some empty spaces and the collagen fibers from derm pass through this layer and penetrate deep between muscle bundles as thick connective tissue septa or myosepta (-Fig. 12).

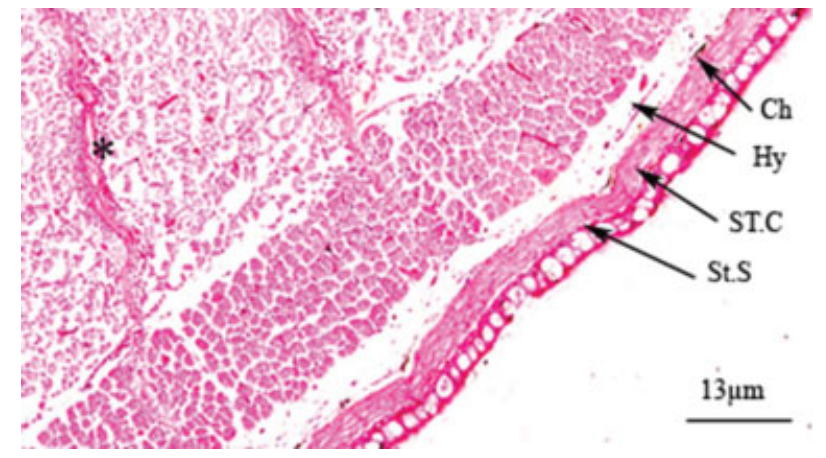

Fig. 12 Histological section of the trunk skin in 40 day larvae (H\&E). Abbreviations: Ch, chromatophore; St.S, stratum spongiosum; St.C, stratum compactum; Hy, hypodermis (*) show myosepta; bar $=13 \mu \mathrm{m}$.

\section{Discussion}

The integument is the first barrier and the outer protective that separates the fish from aquatic environment. There are many descriptions on fish skin and also a few data about the embryonic and larval stages. The aim of this study was to get information about differentiation of epidermis and derm of skin development in Huso huso that is a valuable species of Acipenseridae.

\section{Epidermis Development}

At 1(dph) the epidermis of Huso huso larvae consisted of two cell layers. Some studies showed these layers were formed at different stages, the surface epithelium during the blastula and the inner layer or epidermal basal layer at gastrula period. ${ }^{9}$ The surface layer functions like periderm in mammalian embryo protect the embryo and their cells that arise at mid-blastula, is the first specified cell type, all of the genes affected this development are related to epiboly process. ${ }^{10}$ The basal layer contains both differentiated and undifferentiated cells. Regulation of epidermal basal layer development is regulated by bone morphogenetic protein during gastrulation. ${ }^{11}$

In Huso huso the third row of epidermis and sensory buds were formed from 7 (dph) in head epidermis, this is consistent with previous research on Acipenser percicus that the sensory buds were formed from the end of week $1 .^{12}$ The large circular and elongated cells without positive reaction to carbohydrate staining were present from 10 (dph), these cells could be club cells and ionocyte that in the later stages were increased. Those cells that were covered by surface cells named club cells and those with free surface area and no reaction to PAS named to ionocytes. The first mucous cells with positive reaction to PAS and $A B$ only seemed to apear from 15 (dph), and they could be diagnosed from club cells and ionocytes. In Acipenser percicus also from week- 2 the mucous cells could be distinguished from club cells. ${ }^{12}$ It can be supposed that from the first stages of development, the mucous layer on epidermis was secreted by the undifferentiated epithelial cells to protect the larvae from microorganism infection. The epidermis with three layers was obvious from 20 (dph).

The 25 (dph) - 40 (dph) stages were associated with increasing in cell rows and thickness of epidermis especially in head. At 40 (dph) the skin was evolved and had the adult feature. The epidermis of Huso huso as many other species composed of non keratinized stratified epithelium, Keratinization of fish skin is uncommon, except some species such as the head of Solea senegalensis. ${ }^{13,14}$ The function of keratin is in part compensated by mucous secretion. ${ }^{15}$ In this study, the apparent changes in epithelial thickness were observed from 2 to 10 rows. According to previous findings, epidermal thickness differ based on species, age and body region. ${ }^{16}$ The thickness of head epidermis was greater than trunk, because it can serve as a protection against physical injury and mechanical stress. The stratified epithelium consisted of three layers, it is similar to the findings in other species such as loach (Iksookimia Koreensis), ${ }^{17}$ Senegal sole, ${ }^{13}$ Torrent catfish (Libagrusmedia diposalis) ${ }^{18}$ and eel goby (Odontamblyopus lacepedii). ${ }^{19}$ The intermediate layer was composed of various cells with similar appearance between some of them, 
each of these have specific function. Club cells release alarm signal factors and by olfactory stimulation exhibit a fright reaction, ionocytes are one of the most important cells maintain the homeostasis of body fluids in developmental stages and in Huso huso it can be one of the subtypes of this cell, ${ }^{9}$ mucous cells secret mucus coat that covers the epidermis and the undifferentiated cells can divide and replace the surface cells and intermediate cells. The basal part of epidermis was a single cell layer; the cells of this layer also have the proliferating potential in adult fish. The sensory buds in Huso huso were observed in the head, bronchial and fascial skin. They can be sensory organs of the olfactory system or taste buds.

\section{Dermis Development}

In Huso huso, the presence of the first collagenous fibrils were from 1 (dph). During the first week of development, the primary dermal stroma fills the subepidermal space and the fibrils distributed throughout the thickness irregularly. Between 10-20 days of development, an organization of derm to regular parallel fibrils happened and these events were occurred in a space without cells (fibroblast). Starting from $25(\mathrm{dph})$ the primary derm organized to layers called lamellae and it was invaded by fibroblasts. These modifications lead us to consider the collagenous derm as secondary dermal stroma or stratum compactum.

From the first days of dermis development, some like mesenchymal cells look like fibroblast were found to differentiate to dermal endothelial cells delimits the deep dermal region. In zebrafish (Daniorerio), also at hatching, a primary dermal with different thickness according to body region is perceived, in 5 (dph) the primary derm forms a regular layer and to $10(\mathrm{dph})$ the collagen fibrils organized up to three layers or lamellae. During the following days the number of lamellae are added (Dominique et al., 2004).

According to previous studies on zebrafish, during the early stages of evolution the dermis, cytoplasm of basal layer cells show features revealing active protein synthesis and they can involve in collagen production but with presence the fibroblast in dermal stroma, interaction between epidermis and derm is effective in collagen synthesis and although from one stage to later the epidermal basal cells with contribution the dermal endothelial cells and fibroblasts ceases collagen deposition (Dominique et al., 2004). From the 3 (dph) the chromatophores appeared in the deep of derm, then gradually with more development more cells expanded throughout the hypoderm of head and trunk and also in stratum spongiosum of trunk. The stratum spongiosum only is obvious in trunk but not a conspicuous layer observe in head region, the part of derm lying immediately below the epidermis composed of loose connective tissue and assumed as Stratum spongiosum. A few chromatophore cells are discernible in this region of derm in trunk. The thick dermis of Huso huso causes utilization of skin in leather industry.

\section{Conclusion}

This study aimed to describe the morphogenesis of the skin by light microscopy in one species of sturgeon. It allows us to find the organization and composition of skin. Some findings are agreement with other species, although there are differences from the view of timing. Further analysis are necessary to differences between morphology and the imunohistochemical and also electron microscopy for more precise characterization of skin in Huso huso.

\section{Conflict of Interest}

The authors declare that they have no conflict of interest.

\section{Acknowledgments}

This research is supported by Grant from Ferdowsi University of Mashhad. Thanks to Dr. Fazel Shooraki and Department of histology for practical assistance and Dr. Shahsavani from aquatic department for preparation of samples.

\section{References}

1 Rottmann RW, Francis-Floid R, Dorborow R. The role of stress in fish disease. Mississippi: Southern Regional Aquaculture Center; 1992:474

2 Le Guellec D, Morvan-Dubois G, Sire JY. Skin development in bony fish with particular emphasis on collagen deposition in the dermis of the zebrafish (Danio rerio). Int J Dev Biol 2004;48(23):217-231. Doi: 10.1387/ijdb.15272388

3 Concha MI, Molina S, Oyarzún C, Villanueva J, Amthauer R. Local expression of apolipoprotein A-I gene and a possible role for HDL in primary defence in the carp skin. Fish Shellfish Immunol 2003; 14(03):259-273. Doi: 10.1006/fsim.2002.0435

4 Sire JY, Huysseune A. Formation of dermal skeletal and dental tissues in fish: a comparative and evolutionary approach. Biol Rev Camb Philos Soc 2003;78(02):219-249. Doi: 10.1017/S1464793102006073

5 Whitear M, Mittal AK, Lane EB. Endothelial layers in fish skin. J Fish Biol 1980;17(01):43-65. Doi: 10.1111/j.1095-8649.1980.tb02741.x

6 Bauer ON, Pugachev ON, Voronin VN. Study of parasites and diseases of sturgeon in Russia: a review. J Appl Ichthyology 2002;18(4-6):420-429. Doi: 10.1046/j.1439-0426.2002.00422.x

7 Keyvan A. Iranian sturgeons in the caspiansea: systematic \& biology. Tehran, Iran: Nnaghshe Mehr; 2002

8 Vossoughi GH, Mostajeer HMSB. Fresh water fishes. 8th ed. Tehran: Tehran University; 2009

9 Chang WJ, Hwang PP. Development of zebrafish epidermis. Birth Defects Res C Embryo Today 2011;93(03):205-214

10 Lachnit M, Kur E, Driever W. Alterations of the cytoskeleton in all three embryonic lineages contribute to the epiboly defect of Pou5f1/Oct4 deficient MZspg zebrafish embryos. Dev Biol 2008; 315(01):1-17

11 Sabel JL, d'Alençon C, O'Brien EK, et al. Maternal Interferon Regulatory Factor 6 is required for the differentiation of primary superficial epithelia in Danio and Xenopus embryos. Dev Biol 2009;325(01):249-262. Doi: 10.1016/j.ydbio.2008.10.031

12 Saadatfar Z, Shahsavani D, Fatemi FS. Study of epidermis development in sturgeon (Acipenser persicus) larvae. Anat Histol Embryol 2010;39(05):440-445

13 Arellano J, Storch MV, Sarasquete C. Ultrastructural and Histochemical study on gills and skin of the senegal sole, Solea senegalensis. J Appl Ichthyology 2004;20(06):452-460

14 Whitear M. Functional comparison between the epidermis fish and of amphibians. Symposium of the Zoological Society of London, 1977;39:291-313

15 Carlos A, Strussmann FN, Takashima F. Microscale variation in epidermal thickness, distribution and size of mucus and alarm substance cells in the skin of juvenile Fancy Crap, Copea. Fish Review 1994;40:956-961 
16 Kim CH, Park JY, Park MK, Kang EJ, Kim JH. Minute tubercles tubercles on the skin surface of larvae in the Korean endemic bitterling, Rhodeus Pseudoscriceus. J Appl Ichthyology 2008;24 (03):269-275. Doi: 10.1111/j.1439- 0426.2007.01030.x

17 Park JY. Morphology and histochemistry of the skin of the Korean spined loach, Iksookimia Korcensis (Cobitidae) in relation to respiration. Folia Zool (Brno) 2002;51:241-247
18 Park JY, Lee YJ, Kim IS, Kim SY. Morphological and cytochemical study on the skin of Korean eel goby, Odontamblyopus laceodi (Pisces Gobiidae). Korean J Biol Sci 2003;7: 43-47

19 Park JY, Lee YJ, Kim SI. Structure and Histochemistry of the skin of a Torrent Catis, Liobagrus mediadiposalis. Environ Biol Fishes 2003;66(01):3-8. Doi: 10.1023/A:1023298520696 